\title{
Competition between perch (Perca fluviatilis) and ruffe (Gymnocephalus cernuus): the advantage of turning night into day
}

\author{
D. SCHLEUTER AND R. ECKMANN \\ Limnological Institute, University of Konstanz, Konstanz, Germany
}

\begin{abstract}
SUMMARY
1. The outcome of interspecific competition for food resources depends both on the competitors' sensory abilities and on environmental conditions. In laboratory experiments we tested the influence of daylight and darkness on feeding behaviour and specific growth rate (SGR) of two species with different sensory abilities.

2. We used perch (Perca fluviatilis) as a visually orientated, and ruffe (Gymnocephalus cernuus) as a mechano-sensory oriented predator and tested their growth rates and behaviour under conditions of interspecific and intraspecific competition. Three different foraging conditions were used: food supplied (i) only during the day, (ii) only during the night or (iii) during both day and night.

3. In perch neither SGR nor feeding behaviour were influenced substantially by interspecific competition during daylight. During darkness their foraging behaviour changed markedly and their access to the food source as well as their SGR were negatively affected by the presence of ruffe.

4. Ruffe's foraging behaviour did not change during either day or night with interspecific competition. During the night ruffe's SGR was higher with interspecific competition, probably because of a release from intraspecific competition and the competitive inferiority of perch during the night.

5. Because of its seonsory abilities ruffe feeds predominantly at night, thereby reducing competitive interference from perch.
\end{abstract}

Keywords: aggression, diel light cycle, feeding behaviour, mechanoreception, visual predator

\section{Introduction}

Individuals exploit limited resources against a background of intra- and interspecific competition. The outcome of interspecific competition depends strongly on the seonsory abilities and the behavioural plasticity of the species involved. Additionally, an individual's competitive ability may be modulated by environmental conditions, which generally vary across spatial and temporal scales. Light intensity, for example, shows a regular day-night cycle. In

Correspondence: D. Schleuter, Limnological Institute,

University of Konstanz, D-78457 Konstanz, Germany.

E-mail: diana.schleuter@uni-konstanz.de aquatic habitats it is additionally affected by turbidity and wave action, and it decreases exponentially with water depth (Wetzel, 2001). If two competitors belong to different functional groups such as visual, or mechano-sensory or tactile predators, their competitive success will depend on the competitors' abilities to cope with the particular light conditions and their variation during a $24 \mathrm{~h}$ cycle. Eiane, Aksnes \& Giske (1997) developed a mathematical model describing general competition between fish, as visual and jellyfish as tactile planktivores. Their model demonstrates that the optical properties of the water column are of great importance for the outcome of such competition: visual planktivores outcompete tactile planktivores in clear water with low zooplankton 
abundance, whereas tactile planktivores gain an advantage with increasing light attenuation. Experimental studies on the influence of the light regime on interspecific competition are, however, scarce.

To elucidate the influence of the light regime in aquatic systems on competition between species with different sensory abilities, we selected two co-occurring percids, namely perch (Perca fluviatilis L.) and ruffe [Gymnocephalus cernuus (L.)], for laboratory experiments. Perch is a mobile, visually oriented predator (Thorpe, 1977; Diehl, 1988) that undergoes an ontogenetic diet shift from planktivory through benthivory to piscivory (Collette et al., 1977; Thorpe, 1977; Persson, 1986). Ruffe in contrast has a very well developed lateral line organ and a light sensitive eye because of a tapetum lucidum in the retina (Collette et al., 1977; Disler \& Smirnov, 1977; Bergman, 1988; Gray \& Best, 1989; Janssen, 1997). Ruffe almost exclusively feeds on benthic organisms (Collette et al., 1977; Bergman \& Greenberg, 1994; Hölker \& Thiel, 1998; Kangur, Kangur \& Kangur, 1999). The differences in sensory abilities of perch and ruffe leads to the hypothesis that perch should be the superior competitor in clear, well-lit waters, whereas ruffe should be favoured in an environment with lower light intensity. Bergman (1988) demonstrated niche divergence of the two species in Swedish lakes, with perch occurring in the better illuminated zones of the upper littoral and the pelagic, while ruffe were more abundant in deeper zones with lower light intensity, but only in benthic habitat. In Lake Constance, however, both species co-occur in the shallow littoral zone (Fischer \& Eckmann, 1997). This habitat overlap results in a considerable diet overlap, particularly between the juveniles of both species (D. Schleuter, unpublished data).

After ruffe was accidentally introduced into large lakes, including Lake Superior (U.S.A.), Loch Lomond (Scotland) and Lake Constance (Germany) in the 1980s (Maitland \& East, 1989; Pratt, Blust \& Selgeby, 1992; Roesch \& Schmid, 1996), numerous studies have investigated competition between ruffe and perch [or yellow perch Perca flavescens (Mitchill)] (Bergman \& Greenberg, 1994; Savino \& Kolar, 1996; Fullerton et al., 1998, 2000; Kolar et al., 2002; Dieterich, Mörtl \& Eckmann, 2004). Nevertheless, the competitive relationship between perch and ruffe is still not fully understood, perhaps partly because of the neglect, in earlier studies, of differences between the two species in their sensory physiology and foraging behaviour during day and night. For example, Fullerton et al. $(1998,2000)$ conducted 24-h experiments, but with their experimental set-up they could not analyse competition separately for day and night. They found that neither species was a clearly superior competitor. This is in contrast to the results of Savino \& Kolar (1996), who observed that ruffe were far more aggressive than perch in laboratory experiments and they assumed that ruffe had a competitive advantage because they spent more time at the feeding station. However, their experiments were carried out only under well-lit conditions. The results of Dieterich et al. (2004), who found that perch is the superior competitor on complex substrates (e.g. mussel beds of Dreissena polymorpha PALL.), are likewise only representative of daylight conditions. Bergman (1988) has demonstrated, in single species experiments, that food consumption by ruffe is less affected by decreasing light intensity, when compared with perch, but mixed species experiments testing for a competitive advantage of one or the other species as a function of light conditions are still lacking.

Our study investigated the influence of light regime on the competitive abilities of perch and ruffe, assessing foraging efficiency and competitive behaviour of both species in single and mixed species setups. Three different foraging conditions were used: (i) fish were fed only during day, (ii) fish were fed only during the night, or (iii) fish were fed during both day and night. We proposed four different scenarios for the outcome of competition between the two species: (i) no competitive advantage for either species, because no competitor is superior either during the day or at night; (ii) no competitive advantage for either species, because the competitive superiority of perch during the day is balanced by the competitive superiority of ruffe at night; (iii) competitive advantage for one species, because its superiority during either day or night is not balanced by the other species being superior during the other part of the cycle; (iv) competitive advantage for one species, because it is the superior competitor during both phases of the day-night cycle.

\section{Methods}

The 1+ perch and 1+ ruffe used in this study were caught in Lake Constance, Germany with a lift net at 
least 5 months before the experiments started. The fish were acclimated to laboratory conditions in $100 \mathrm{~L}$ aquaria under a natural day-night cycle and they were fed with frozen chironomid larvae.

The experiments were carried out in $72 \mathrm{~L}$ aquaria, the bottoms of which were covered with a $2 \mathrm{~cm}$ deep layer of sand and pebbles of up to $4 \mathrm{~mm}$ particle size. To avoid visual contact between experimental groups, the sidewalls of the aquaria were covered with black plastic film. The aquaria were supplied with filtered lake water at a rate of $0.4 \mathrm{~L} \mathrm{~min}^{-1}$, the water temperature was held constant at $19{ }^{\circ} \mathrm{C}$, and light from a daylight fluorescent tube was provided from 08:00 hours to 19:00 hours local time, so that the room was evenly illuminated with 600 lux. During night, complete darkness (0 lux) was reached through elimination of any source of light. During the experiments the fish were fed with living chironomid larvae, which were obtained from a commercial supplier every week.

To provoke competition for food, fish were fed a suboptimal ration, which was calculated using the model Fish Bioenergetics 3.0 (Hanson et al., 1997). Because the physiology of Eurasian and yellow perch is very similar (Thorpe, 1977), the model parameters for yellow perch were considered appropriate for Eurasian perch. As no bioenergetics model for ruffe was available, the calculations for ruffe were also based on the model parameters for yellow perch. Hence, based on the yellow perch bioenergetics model, $75 \%(P=0.75)$ of the maximum daily food ration was provided per day. In the experiments where food was provided during day and night, the daily food ration was separated into two equal halves, otherwise the entire ration was given at one time.

The food was provided in sand filled Petri dishes of $14 \mathrm{~cm}$ diameter. The dishes were initially placed in a separate aquarium and each surrounded by a cylinder of gauze, which was slightly taller than the aquarium. Then the weighed (to $0.1 \mathrm{mg}$ ) rations of chironomids were poured into the cylinders. The chironomid larvae were allowed to burrow into the sand during daylight or during the night, respectively, then every morning and evening a new feeding dish with the surrounding gauze was introduced into each experimental aquarium. As soon as the chironomids that had not burrowed into the sand $(<5 \%)$ had settled down on top of the sediment, the gauze was removed so that the fish had access to the food source.
Differences in burrowing behaviour of chironomids between day and night could not be observed. In treatments where food was provided only once per day, either during the light or the dark period, a sand filled Petri dish without food was introduced in the morning or evening, respectively, a procedure which was adopted to standardise experimental handling across all set-ups. To determine the food consumed during each feeding cycle, the chironomids remaining in the Petri dish at the end of the cycle were picked from the dish by hand and weighed to the nearest $0.1 \mathrm{mg}$.

The experimental design was fully factorial with two factors at each of three levels: fish species (four perch, four ruffe, two perch plus two ruffe) and feeding regime (only during the day, only during the night, during both day and night). Thus, nine different factor combinations were used, and these were replicated three times, each replicate lasting for 3 weeks. The treatments were assigned randomly to the aquaria for each replicate.

For behavioural analysis, video recordings were taken of experiments where fish were fed during the day and night with recordings being made for 1 day during each of the first and the third weeks of the second and third replicates. The aquarium was observed for $24 \mathrm{~h}$, from above, using an infrared sensitive camera and a time-lapse video recorder. At night the visual field of the camera was illuminated with infrared lights $(\lambda>850 \mathrm{~nm})$, mounted around the camera lens. In addition to the time lapse recordings, fish behaviour was videotaped through the front wall of the aquarium at 08:00, 08:15, 08:30, 08:45, 09:00, 11:00, 13:00, 15:00 and 17:00 hours for 5 min each time.

For acclimatisation, fish of similar size and weight were transferred to the experimental aquaria 1 week before an experiment started. To allow for individual analyses of weight gain, fish were anaesthetised with 2-phenoxyethanol $\left(0.3 \mathrm{~mL} \mathrm{~L}^{-1}\right)$ and marked individually with fin clips. To adapt the fish to the experimental protocol, food was provided in the same way as during the experiments. The experimenter entered the room in the morning and switched on a dim light. The feeding dishes were removed from the aquaria, the fish were gently corralled with gauze frames to the front parts of the aquaria, and the new feeding dishes were put into place. When everything was ready, the gauze frames were removed, the room light was 
switched on, and the experimenter left the room. In the evening the same procedure was repeated with the room light switched off after the fish were allowed access to the feeding dishes.

On the evening before an experiment started, the fish were anaesthetised, measured to the nearest $0.1 \mathrm{~cm}$ and weighed to the nearest $0.1 \mathrm{~g}$, having been starved for $24 \mathrm{~h}$ before weighing to ensure that they had empty stomachs (Persson, 1979; Henson \& Newman, 2000). Initial mean standard length of perch was $8.3 \pm 0.7 \mathrm{~cm}$, initial mean body mass $8.1 \pm 2.0 \mathrm{~g}$ (mean $\pm \mathrm{SD}$ ), of ruffe $7.3 \pm 0.5 \mathrm{~cm}$ and $7.3 \pm 1.5 \mathrm{~g}$, respectively. After the 3-week experiment the fish were starved for $24 \mathrm{~h}$, anaesthetised and weighed again. The specific growth rate (SGR) for each fish was calculated as: SGR $=\left(\log _{\mathrm{e}} Y_{2}-\log _{\mathrm{e}} Y_{1}\right) / \Delta t$, where $Y_{1}$ and $Y_{2}$ are the initial and final body masses, and $\Delta t$ is the duration of the experiment in days (Busacker, Adelman \& Goolish, 1990).

The time-lapse video observations were analysed every half hour for $180 \mathrm{~s}$. The variables measured were: frequency of visits to the feeding dish FV (mean number of visits per fish during $180 \mathrm{~s}$ ), duration of visits to the feeding dish DV (mean time a fish spent at the dish per visit) and total time per fish at the feeding dish TT (mean total time per fish). TT is not simply the product of FV and DV, because the zero values of FV are not included in the calculation of DV. Hence, TT in some cases is lower than the product of FV and DV. Aggressive behaviour was examined from the video recordings through the front wall of the aquarium. Aggression was defined as one fish chasing another with an erect dorsal fin. The number of aggressive acts during $5 \mathrm{~min}$ was counted per species. In the mixed species set-ups, aggressive acts against conspecifics and heterospecifics were evaluated separately.

The program JMP 4.0 was used for statistical analysis of the data. All data except for aggressive acts were analysed by one-way ANOVA. In cases of unequal variances, the data were arcsine-transformed (percentage of food consumed) or log-transformed (FV perch). For further comparisons between set-ups (post hoc tests), contrast analysis (ANOvA CA) was used (Bonferroni corrected). Before pooling data across replicates or across time within one experiment, replicates, or time of observation (video recordings during the first or third week of an experiment), were tested as additional factors. For the analysis of food consumption, mean values for an experiment, and for the analysis of feeding behaviour, mean values for the day and the night phases separately were used. Differences between species were tested with $t$-tests or Kruskal-Wallis ANOvA.

Observations on aggressive behaviour were analysed separately for the first hour after food was given and then for the rest of the day (from 09:00 hours to 17:00 hours). Differences between inter- and intraspecific competition, single and mixed species treatments and between species were compared with t-tests or Kruskal-Wallis ANOVA.

\section{Results}

Both the perch and ruffe adjusted well to the experimental protocol and showed no symptoms of stress after the second or third day of the acclimatisation period. They learnt quickly to look for food in the Petri dishes.

\section{Specific growth rates}

The SGRs of perch ranged from $0.28 \pm 0.26$ (mean \pm SD) to $0.42 \pm 0.18$ in the single species setups and from $-0.43 \pm 0.24$ to $0.41 \pm 0.34$ in the mixed species set-ups (Fig. 1). The SGRs of the ruffe ranged from $0.69 \pm 0.17$ to $1.02 \pm 0.08$ in the single species set-ups and from $0.87 \pm 0.15$ to $1.43 \pm 0.37$ in the mixed species set-ups (Fig. 1). Perch's SGRs were lower in the mixed species set-ups compared with the single species set-ups (one-way ANOvA, $P=0.020$ )

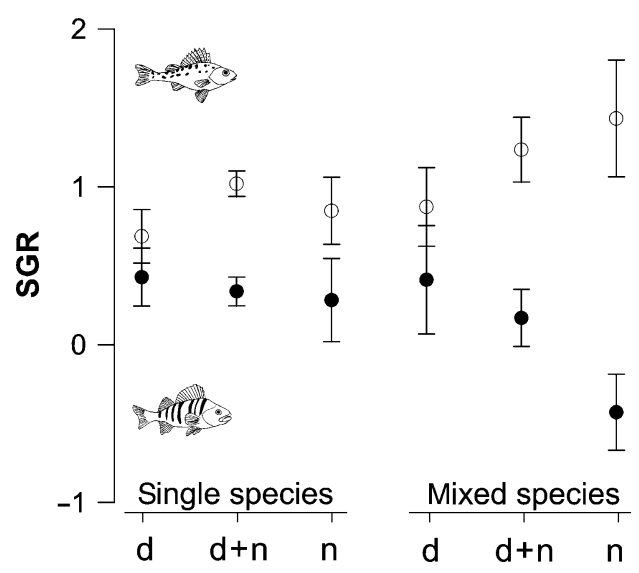

Fig. 1 Mean $( \pm S D)$ specific growth rates (SGR) of perch (closed circles) and ruffe (open circles) in single and mixed species setups. $d$, feeding during the day; $d+n$, feeding during the day and at night; $n$, feeding during the night. 
Table 1 Results of one-way ANOvAs, testing differences of specific growth rates of perch and ruffe, between species and for each species separately

\begin{tabular}{lrrrr}
\hline Source & d.f. & SQ & $F$-value & $P$-value \\
\hline Perch & & & & \\
$\quad$ 1-/2-species set-up & 1 & 0.4009 & 7.495 & 0.018 \\
$\quad$ Time of feeding & 2 & 0.7531 & 7.040 & 0.009 \\
1-/2-species set-up $\times$ time of feeding & 2 & 0.3993 & 3.732 & 0.055 \\
$\quad$ Residuals & 12 & 2.1952 & & \\
Ruffe & & & & \\
1-/2-species set-up & 1 & 0.4876 & 9.106 & 0.011 \\
$\quad$ Time of feeding & 2 & 0.5025 & 4.692 & 0.031 \\
1-/2-species set-up $\times$ time of feeding & 2 & 0.1480 & 1.382 & 0.288 \\
$\quad$ Residuals & 12 & 1.7809 & & \\
Perch, ruffe (single and mixed) & & & & \\
$\quad$ Species & 3 & 6.8752 & 42.818 & 0.000 \\
$\quad$ Time of feeding & 2 & 0.1482 & 1.384 & 0.270 \\
$\quad$ Species $\times$ time of feeding & 6 & 1.6548 & 5.153 & 0.002 \\
$\quad$ Residuals & 35 & 9.9628 & & \\
\hline
\end{tabular}

and decreasing from the treatment when food was provided only during the day to the treatment when food was provided only during the night (one-way ANOva, $P=0.010$ ). This trend was even more pronounced in the mixed species set-ups: when fed during the day, perch reached growth rates equal to those in the single species treatments (ANOvA CA, $P=0.931$ ), but when fed only at night the perch grew less than in all other treatments and lost weight (Fig. 1). Ruffe, by contrast, grew least when fed only during the day (one-way ANOvA, $P=0.010$ ), and they grew better in the mixed species set-up when compared with the single species treatments (one-way AnOva, $P=0.003$; Fig. 1; Table 1).

Thus, the SGRs of perch and ruffe showed opposite trends under interspecific competition. Perch SGR decreased from the day to the night feeding treatment, while ruffe SGR increased. In all treatments the ruffe SGRs were significantly higher than those of perch $(t-$ test, $P<0.05$; Fig. 1).

\section{Food consumption}

The foraging ability of perch was greatly reduced during darkness (Fig. 2). In the single species treatment, perch consumed nearly all the chironomids $(93.3 \pm 4.8 \%$; mean $\pm \mathrm{SD})$ when food was supplied during the day. However, they consumed significantly less when food was given during the day and night $(76.0 \pm 8.8 \%$, ANOv A CA, $P=0.007)$, and when food was supplied only during the night $(66.2 \pm 16.5 \%$, ANOva CA, $P=0.000)$. In the ruffe and in the mixed species treatments, in contrast,

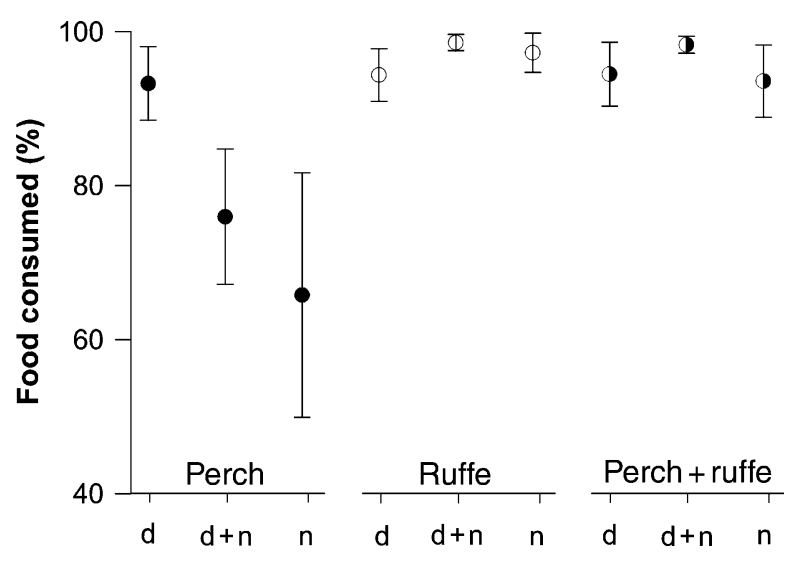

Fig. 2 Mean $( \pm \mathrm{SD})$ of the percentage of chironomids consumed in single perch, single ruffe and mixed species treatments. $d$, feeding during the day; $d+n$, feeding during the day and at night; $n$, feeding during the night.

always more than $90 \%$ of the chironomids were consumed irrespective of the feeding regime (ANOVA CA, $P>0.05$; Fig. 2).

\section{Feeding behaviour}

Perch and ruffe showed different feeding behaviours. Perch swam to the feeding dish, inclined the body to pick up the chironomids they had spotted, and returned into a horizontal position in the water column. Quite often, particularly after introduction of the feeding dish, three or four perch approached the dish to feed at the same time. In contrast ruffe swam to the feeding dish and moved slowly around, ruffe visited the feeding place at the same time. close to the bottom. In most cases, no more than two 
The different behaviours of perch and ruffe can be described through the variables FV (Fig. 3a; Table 2) and DV (Fig. 3b; Table 2). For perch, the day values of both variables (mean $\pm \mathrm{SD}$ ) did not differ significantly between the single and mixed species treatments (FV:
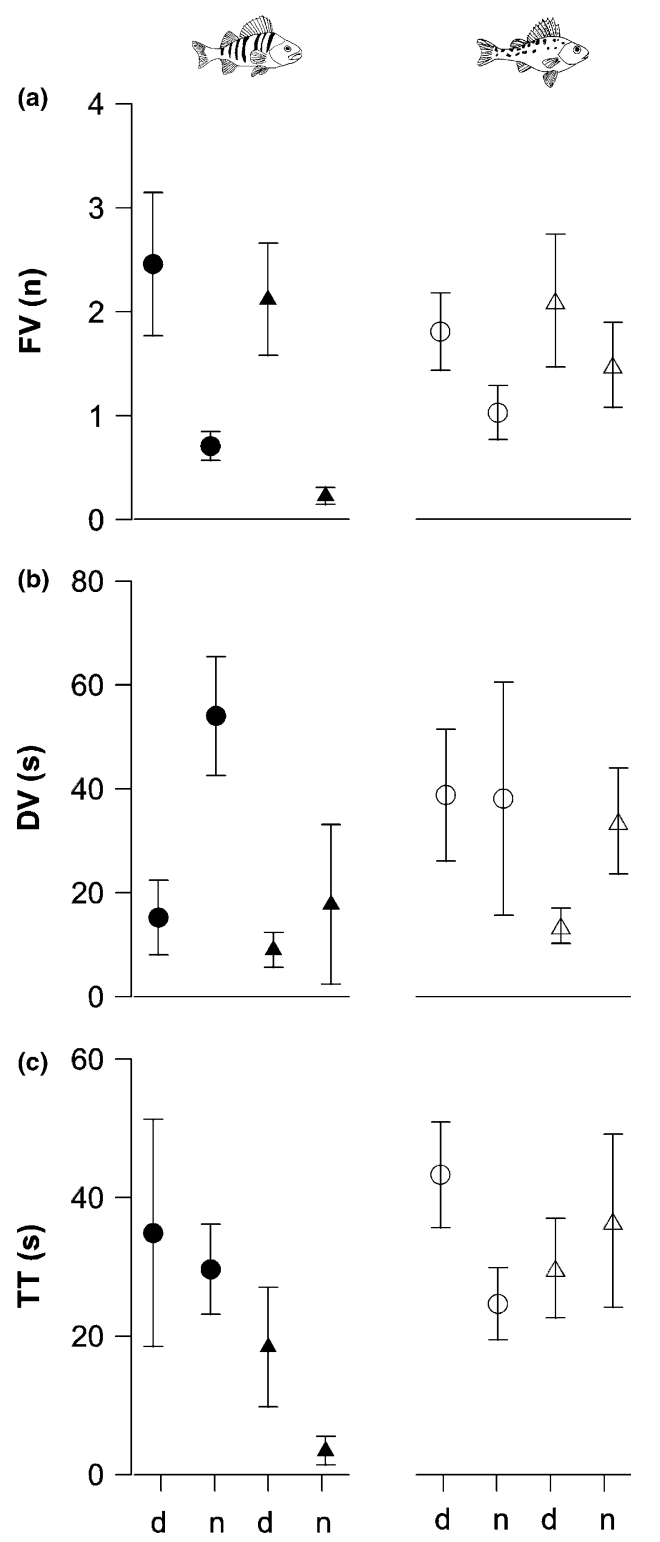

Fig. 3 Feeding behaviour of perch and ruffe (day + night feeding treatment). (a) Mean $( \pm S D)$ of the number of visits to the feeding dish per fish per $180 \mathrm{~s}$; (b) Mean $( \pm$ SD) of the duration of visits to the feeding dish per fish per $180 \mathrm{~s}$; (c) Mean $( \pm \mathrm{SD})$ of total time spent at the feeding dish per fish per $180 \mathrm{~s}$. Closed circles $=$ perch in single species set-ups; closed triangles $=$ perch in mixed species set-ups; open circles = ruffe in single species set-ups; ruffe $=$ open triangles mixed species set-ups. $\mathrm{d}=$ observation during daytime, $\mathrm{n}=$ observation during the night.
$2.5 \pm 0.7$ versus $2.1 \pm 0.5$, ANOvA CA, $P=0.475$; DV: $15.2 \pm 7.2$ versus $9.0 \pm 3.4 \mathrm{~s}$ per fish, ANOVA CA, $P=$ 0.414 ), while the night values did (ANOVA CA, FV: $P<0.001$; DV: $P<0.001$ ). When together with conspecifics, perch visited the feeding dish less often during the night than during the day (FV: $0.7 \pm 0.1$ versus $2.5 \pm 0.7$; ANOva $C A, P<0.001$ ), and they spent significantly more time at the feeding place during the night than during daytime (DV: $54.1 \pm 11.5$ versus $15.2 \pm 7.2 \mathrm{~s}$; ANOva $C A, P<0.001)$. From the video recordings it was obvious that perch often rested in the feeding dish during the night and sometimes did not move at all during a $180 \mathrm{~s}$ observation period.

When together with ruffe, however, the perch visited the feeding dish less often during the night when compared with the single species set-up (FV: $0.2 \pm 0.1$ versus $0.7 \pm 0.1$, ANOva CA, $P<0.001$ ). The time perch spent at the feeding place during nights was similar to the day value, and was significantly lower when compared with the single species set-up (DV: $17.8 \pm 15.4$ versus $54.1 \pm 11.5 \mathrm{~s}$, ANOVA CA, $P<0.001)$. The total time perch spent at the feeding place did not differ significantly between day and night in the single and mixed species set-ups (Table 2). In the mixed species set-up, however, perch tended to spend less time at the feeding dish during the night (TT: $18.4 \pm 8.6$ versus $3.5 \pm 2.1 \mathrm{~s}$ ), although the result was not significant (Table 2). Altogether perch spent significantly less time at the feeding dish when ruffe were present (Fig. 3c; Table 2).

For ruffe, FV did not differ between intra- and interspecific competition $(1.8 \pm 0.4$ versus $2.1 \pm 0.6$ during day, $1.0 \pm 0.3$ versus $1.4 \pm 0.4$ during night; Fig. 3a; Table 2). Under both conditions, ruffe visited the feeding dish less often during the night (one-way ANOVA, $P=0.014$ ). DV and TT were not influenced either by the time of day or by the presence of perch (Table 2, for TT the interaction term was not significant after Bonferroni correction).

When comparing the behaviour of these two species it can be seen that in the single species set-ups perch tended to visit the feeding dish more frequently during the day than did ruffe and, in all experiments, perch tended to visit the feeding place less frequently during night. However, the only significant difference was for FV during the night between the mixed species set-ups ( $t$-test, $P<0.001$; Fig. $3 a)$. DVs were generally longer for ruffe than for perch (except for 
Table 2 Results of one-way ANovas, testing differences in feeding behaviour between perch and ruffe

\begin{tabular}{|c|c|c|c|c|}
\hline Source & d.f. & SQ & $F$-value & $P$-value \\
\hline \multicolumn{5}{|l|}{ Frequency of visits $(F V)$} \\
\hline \multicolumn{5}{|l|}{ Perch } \\
\hline Time of day & 1 & 2.2869 & 152.9328 & 0.000 \\
\hline $1-/ 2$-species set-up & 1 & 0.3263 & 21.8232 & 0.001 \\
\hline Time of feeding $\times 1-/ 2$-species set-up & 1 & 0.1969 & 13.1679 & 0.004 \\
\hline Residuals & 12 & 0.1794 & & \\
\hline \multicolumn{5}{|l|}{ Ruffe } \\
\hline Time of day & 1 & 1.7963 & 8.5835 & 0.014 \\
\hline 1-/2-species set-up & 1 & 0.5332 & 2.5477 & 0.139 \\
\hline Time of feeding $\times 1-/ 2$-species set-up & 1 & 0.0222 & 0.1060 & 0.751 \\
\hline Residuals & 11 & 2.3021 & & \\
\hline \multicolumn{5}{|l|}{ Duration of visit (DV) } \\
\hline \multicolumn{5}{|l|}{ Perch } \\
\hline Time of day & 1 & 2265.9980 & 21.0620 & 0.001 \\
\hline 1-/2-species set-up & 1 & 1803.4886 & 16.7631 & 0.002 \\
\hline Time of feeding $\times 1-/ 2$-species set-up & 1 & 903.7539 & 8.4002 & 0.013 \\
\hline Residuals & 12 & 1291.0445 & & \\
\hline \multicolumn{5}{|l|}{ Ruffe } \\
\hline Time of day & 1 & 349.6214 & 2.0963 & 0.176 \\
\hline 1-/2-species set-up & 1 & 800.6775 & 4.8008 & 0.051 \\
\hline Time of feeding $\times 1-/ 2$-species set-up & 1 & 401.2182 & 2.4057 & 0.149 \\
\hline Residuals & 11 & 1834.5898 & & \\
\hline \multicolumn{5}{|l|}{ Total time per fish (TT) } \\
\hline \multicolumn{5}{|l|}{ Perch } \\
\hline Time of day & 1 & 408.2420 & 4.1876 & 0.063 \\
\hline $1-/ 2$-species set-up & 1 & 1819.8756 & 18.6674 & 0.001 \\
\hline Time of feeding $\times 1-/ 2$-species set-up & 1 & 94.8676 & 0.9731 & 0.343 \\
\hline Residuals & 12 & 1169.8723 & & \\
\hline \multicolumn{5}{|l|}{ Ruffe } \\
\hline Time of day & 1 & 129.2200 & 1.6706 & 0.223 \\
\hline $1-/ 2$-species set-up & 1 & 2.0447 & 0.0264 & 0.874 \\
\hline Time of feeding $\times 1-/ 2$-species set-up & 1 & 13.8012 & 17.0309 & 0.018 \\
\hline Residuals & 11 & 850.8235 & & \\
\hline
\end{tabular}

perch during the night in the single species set-up), but they were significantly different only between single species set-ups during daytime (DV: $15.2 \pm 7.2$ versus $38.8 \pm 12.7 \mathrm{~s}$; $t$-test, $P=0.018$; Fig. $3 \mathrm{~b}$ ). TT did not differ between species in the single species set-ups (t-test, day: $P=0.388$; night: $P=0.329$ ). When together with ruffe, however, perch TT was significantly lower at night (TT: $3.4 \pm 2.06$ versus $36.6 \pm 12.5 \mathrm{~s} ; \quad$ Kruskal-Wallis ANOvA, $P=0.021$; Fig. 3c).

\section{Aggression}

The numbers of aggressive acts (Fig. 4) did not differ between perch and ruffe in the single species treatments $(1.9 \pm 1.9$ aggressive acts per fish per $5 \mathrm{~min}$ for perch versus $1.8 \pm 1.5$ for ruffe; Kruskal-Wallis ANOVA, $P=0.901$ ) but they decreased for perch and increased for ruffe in the mixed species treatments, although for both species the differences were not significant (Kruskal-Wallis ANOVA, perch: $P=0.131$, ruffe: $P=0.855)$. When comparing the mixed species set-ups only, perch were less aggressive than ruffe ( $t$-test: $P=0.050$ ).

Perch attacked their conspecifics more often than they attacked ruffe $(0.9 \pm 0.9$ versus $0.3 \pm 0.6$ aggressive acts; Kruskal-Wallis ANOvA, $P=0.001$ ), while ruffe did not discriminate between conspecifics and heterospecifics $(1.4 \pm 2.1$ intra- and interspecific aggressive acts; $t$-test, $P=0.929$ ). For perch, the number of aggressive acts was similar directly after food supply and later in the day under both experimental set-ups (single species: $t$-test, $P=0.457$; mixed species: Kruskal-Wallis ANOVA, $P=0.491$ ). Ruffe, however, were more aggressive after food supply than later in the day (single species: $t$-test, $P<0.001$; mixed species: Kruskal-Wallis ANOvA, $P<0.001)$. 

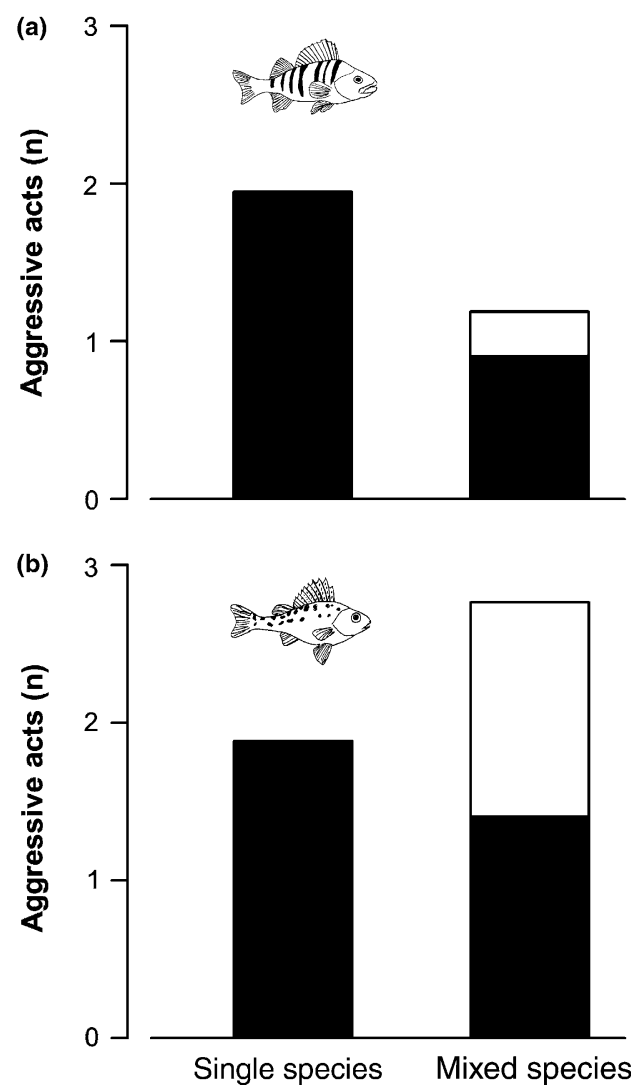

Fig. 4 Mean number of aggressive acts per fish per $5 \mathrm{~min}$ for single and mixed species treatments (day + night feeding treatment). Filled columns show intra-specific aggression, clear columns show interspecific aggression. (a) perch and (b) ruffe.

\section{Discussion}

The results of this study demonstrate that the outcome of competition for food depends on the competitors' sensory abilities to cope with particular environmental conditions. In the present case, the different abilities of perch and ruffe to detect prey, by visual or mechano-sensory cues respectively, were decisive for the species' feeding success during day and night. During the day neither SGRs nor feeding behaviour of perch and ruffe were influenced substantially by interspecific competition. During the night, however, feeding behaviour and SGRs of perch were strongly negatively influenced by the presence of ruffe. For ruffe, in contrast, SGRs increased with interspecific competition, although there was no significant effect on the variables describing feeding behaviour. Our results therefore supported the hypothesised scenario iii, with ruffe being favoured because of its superiority during the night, while perch was an equal but not superior competitor during day.

Several experiments have attempted to understand the feeding behaviour of perch and ruffe in daylight. Our experiments on the feeding behaviour of perch and ruffe in mixed species set-ups did not detect any effect of interspecific competition under daylight conditions, which is similar to the results of Savino \& Kolar (1996). Whereas in the experiments of Savino \& Kolar (1996) time per visit (DV) and total time (TT) spent at the feeding place decreased for ruffe with interspecific competition, in our study these variables also tended to decrease but the differences were not significant. However, the present study clearly showed how feeding behaviour of both species changed completely during darkness, and that these changes can only be detected when the night-time period is explicitly considered in the experimental design.

\section{Intraspecific competition}

In the single species treatments the SGR of perch was reduced when they were fed only at night, most probably because of the small amount of food consumed (66\%, cf. Fig. 2). This is in accordance with the results of Diehl (1988) who observed similar low prey capture rates for perch during darkness. Our behavioural observations revealed reduced activity of perch during the night, with fewer but longer visits to the feeding dish (probably indicating resting behaviour). It is well known from field studies that perch are active during twilight and daytime and that they rest at night (Thorpe, 1977; Jamet \& Lair, 1991; Imbrock, Appenzeller \& Eckmann, 1996; Dörner, Wagner \& Benndorf, 1999). Accordingly, field observations of empty stomachs in the morning indicate no food intake during the night (Jamet \& Lair, 1991, D. Schleuter, unpublished data). In contrast, laboratory studies by, for example, Diehl (1988) and Janssen (1997), like the results presented here, reported food intake by perch during darkness. These observations should, however, be considered as laboratory artefacts caused by the experimental conditions where predators and prey were confined to a rather limited space. Under these conditions it is possible even for a predominantly visually oriented predator such as perch to find prey with its unspecialised - compared with ruffe - lateral line organ (Janssen, 1997). For 
ruffe, which seem to detect their prey with their lateral line organ or through chemoreception rather than through vision, there was no influence of light regime in the intraspecific competition treatments.

\section{Interspecific competition}

In the mixed species set-ups the effect of darkness on the feeding behaviour of perch was even more marked than in the single species set-ups. Perch visited the feeding dish even less frequently, but their visits were not longer than during the day because they were chased off by the ruffe. When food was only available during the night, perch seemed unable to consume enough food to meet their daily metabolic costs, leading to negative SGRs. The feeding behaviour of ruffe, in contrast, did not change with competition from perch. Although the total time spent at the feeding dish was the same as for the single species treatments, ruffe achieved higher growth rates in the mixed species treatments. This is probably because of higher food consumption by ruffe under interspecific competition where they consumed at least part of the perch's ration as well. Hence, for ruffe, intraspecific competition had a stronger impact during the night than interspecific competition. In the mixed species set-ups, perch hardly visited the feeding dishes at all during the night, and thus ruffe experienced less competition than in the single species set-ups. Consequently, ruffe gained an additional advantage as they could invest more time in feeding because time needed to defend the food source was reduced.

Bergman (1988), in contrast, observed that the prey capture rate of ruffe decreased with decreasing light level, although ruffe were less affected by changing light conditions than perch. The discrepancy between these results and our observations is probably because of the different prey organisms used in the two studies. Bergman used two mobile species as prey, Daphnia magna and Chaoborus obsuripes, while in the present study chironomid larvae were used. The chironomids had buried themselves in the sand where ruffe could easily detect them even in complete darkness by using their lateral line organ while gliding over the sediment (Gray \& Best, 1989; Janssen, 1997).

The fact that both species were equal competitors during the day is surprising. Based upon the model produced by Eiane et al. (1997), perch were expected to be the superior competitor during the day. Furthermore, earlier laboratory studies had shown that perch are more active (Bergman, 1987, 1988; Savino \& Kolar, 1996) and have higher prey capture rates than ruffe under well lit conditions and at the same temperature (Bergman, 1987, 1988). However, the high capture rates of perch in comparison with ruffe in the studies of Bergman might have been caused also by the readily visible prey types used in her experiments. Savino \& Kolar (1996) and Fullerton et al. (2000), in contrast, had already observed that one species was not superior to the other, although Savino \& Kolar (1996) observed higher prey capture rates for ruffe. In addition, they measured shorter handling times for ruffe and observed kleptoparasitism. The aggressive behaviour of ruffe is the most likely reason for the lower capture rates by perch. In the present study, ruffe were more aggressive in the presence of perch and addressed their aggression equally to perch and to conspecifics. Perch, in contrast, aimed their aggression mainly at conspecifics, whereby they often restricted their access to the feeding dish. Frequently, the perch chased each other around the feeding dish; meanwhile ruffe were feeding. This kind of interference competition is probably less important in the field, because the daytime activity levels of ruffe were probably higher in our laboratory experiments than under natural conditions. Firstly, the fish had become used to daytime activity, as feeding and handling during acclimatisation to laboratory conditions was mostly conducted during the day, and, secondly, the daytime activity of perch might have influenced ruffe activity as well. Most field studies indicate that ruffe mainly feed at night, as can be deduced from full stomachs in the morning and relatively scarcely filled stomachs in evening samples (Jamet \& Lair, 1991; Ogle et al., 1995; D. Schleuter, unpublished data). Additionally, low activity of ruffe during daytime was observed in Lake Constance, where ruffe were shoaling under footbridges, macrophytes or artificial reefs, moving very slowly if at all (A. Weber and D. Schleuter, personal observation). However, although agonistic behaviour in nature might be less pronounced compared with laboratory studies, it will still play an important role in competitive interactions, for example during twilight, when both species are active. In previous studies aggressive interactions were often neglected, but we could show the import- 
ance of including agonistic behaviour in the analysis of resource competition between perch and ruffe.

In the Swedish lakes sampled by Bergman (1988), perch and ruffe avoided or reduced interspecific competition by the use of different habitats. Perch were found in the lighter, shallower regions of the lake, where they used the pelagic and benthic zones, whereas ruffe were more abundant in the darker parts of the lake where they used the benthic zone. Bergman (1991) and Bergman \& Greenberg (1994) suggested that in turbid water ruffe would restrict the access of perch to the common benthic food source, and they showed that ruffe abundance increased with lake productivity.

In Lake Constance both percid species live together in the littoral zone but they have different activity patterns (Fischer \& Eckmann, 1997; D. Schleuter, unpublished data). Perch are active during twilight and during the day, whereas ruffe are active during twilight and at night. Therefore, ruffe can exploit food resources during the night very efficiently, while perch seem to be unable to catch up during day. Food consumption rates of perch during the day might, however, be higher in the field than in our experiments, because the high activity of ruffe during daytime was probably an artefact of the laboratory conditions. However, the results of our night-feeding treatments clearly show that ruffe have an advantage, because their interference competition seems to be greatly reduced because of the resting behaviour of perch during the night. Bergman (1987) found ruffe to be a temperature generalist in comparison with perch. This will play a minor role in Lake Constance, where both species co-occur in the same habitat. In our experiments we used $19{ }^{\circ} \mathrm{C}$, which is characteristic of the species' habitat during the growing season.

In conclusion, this study underlines the importance of considering the variability of environmental conditions during the diel cycle when designing laboratory studies aimed at analysing the behavioural mechanisms of resource competition. This is especially important when competitors with different sensory abilities are compared, because competitive success can be strongly dependent on a match between a competitor's sensory abilities and the particular environmental conditions during different periods of the day. For example, the present results demonstrate the advantage that ruffe gain from a sensitive lateral line organ, which allows the fish to avoid interference competition from perch by feeding at night. In contrast to the Swedish lakes, where due to different habitat use of perch and ruffe interference and exploitative competition is reduced (Bergman, 1988), in Lake Constance primarily interference competition is alleviated because of different activity patterns.

\section{Acknowledgments}

We thank Christine Baderschneider, Anne Berking, Chirstian Bruckner and Oliver Miler for their assistance in the performance of the experiments and the analysis of the video tapes. We further thank Colin Townsend and two anonymous referees whose valuable comments improved the manuscript. This study was supported by the Deutsche Forschungsgemeinschaft within the collaborative research centre SFB 454 'Littoral of Lake Constance'.

\section{References}

Bergman E. (1987) Temperature-dependent differences in foraging ability of two percids, Perca fluviatilis and Gymnocephalus cernuus. Environmental biology of Fishes, 19, 45-53.

Bergman E. (1988) Foraging abilities and niche breadth of two percids, Perca fluviatilis and Gymnocephalus cernua, under different environmental conditions. Journal of Animal Ecology, 57, 443-453.

Bergman E. (1991) Changes in abundance of two percids, Perca fluviatilis and Gymnocephalus cernuus, along a productivity gradient: relations to feeding strategies and competitive abilities. Canadian Journal of Fisheries $\mathcal{E}$ Aquatic Sciences, 48, 536-545.

Bergman E. \& Greenberg L.A. (1994) Competition between a planktivore, a benthivore, and a species with ontogenetic diet shifts. Ecology, 75, 1233-1245.

Busacker G.P., Adelman I.R. \& Goolish E.M. (1990) Growth. In: Methods for Fish Biology (Eds C.B. Schreck \& P.B. Moyle), pp. 363-387. American Fisheries Society, Bethesda, Maryland, U.S.A.

Collette B.B., Ali M.A., Hokanson K.E.F., Nagiec M., Thorpe J.E., Weatherley A.H. \& Willemsen J. (1977) Biology of the percids. Journal of the Fisheries Research Board of Canada, 34, 1890-1899.

Diehl S. (1988) Foraging efficiency of three freshwater fishes: effects of structural complexity and light. Oikos, 53, 207-214.

Dieterich A., Mörtl M. \& Eckmann R. (2004) The effects of zebra mussels (Dreissena polymorpha) on the foraging 
success of Eurasian perch (Perca fluviatilis) and ruffe (Gymnocephalus cernuus). International Review of Hydrobiology, 89, 229-237.

Disler N.N. \& Smirnov S.A. (1977) Sensory organs of the lateral-line canal system in two percids and their importance in behavior. Journal of the Fisheries Research Board of Canada, 34, 1492-1503.

Dörner H., Wagner A. \& Benndorf J. (1999) Predation by piscivorous fish on age-0 fish: spatial and temporal variability in a biomanipulated lake (Bautzen reservoir, Germany). Hydrobiologia, 408-409, 39-46.

Eiane K., Aksnes D.L. \& Giske J. (1997) The significance of optical properties in competition among visual and tactile planktivores: a theoretical study. Ecological Modelling, 98, 123-136.

Fischer P. \& Eckmann R. (1997) Spatial distribution of littoral fish species in a large European lake, Lake Constance, Germany. Archiv Für Hydrobiologie, 140, 91116.

Fullerton A.H., Lamberti G.A., Lodge D.M. \& Berg M.B. (1998) Prey preferences of Eurasian ruffe and yellow perch: comparison of laboratory results with composition of Great Lakes benthos. Journal of Great Lakes Research, 24, 319-328.

Fullerton A.H., Lamberti G.A., Lodge D.M. \& Goetz F.W. (2000) Potential for resource competition between Eurasian ruffe and yellow perch: growth and RNA responses in laboratory experiments. Transactions of the American Fisheries Society, 129, 1331-1339.

Gray J.A.B. \& Best A.C.G. (1989) Patterns of excitation of the lateral line of the ruffe. Journal of the Marine Biological Association of the U.K., 69, 289-306.

Hanson P.C., Johnson T.B., Schindler D.E. \& Kitchell J.F. (1997) Fish Bioenergetics, 3rd edn. University of Wisconsin Sea Grant Institute, Madison, WI.

Henson F.G. \& Newman R.M. (2000) Effect of temperature on growth at ration and gastric evacuation rate of ruffe. Transactions of the American Fisheries Society, 129, 552-560.

Hölker F. \& Thiel R. (1998) Biology of ruffe [Gymnocephalus cernuus (L.)]. A review of selected aspects from European literature. Journal of Great Lakes Research, 24, 186-204.

Imbrock F., Appenzeller A. \& Eckmann R. (1996) Diel and seasonal distribution of perch in Lake Constance: a hydroacoustic study and in situ observations. Journal of Fish Biology, 49, 1-13.

Jamet J.L. \& Lair N. (1991) An example of diel feeding cycle of two percids, perch (Perca fluviatilis) and ruffe (Gymnocephalus cernuus) in eutrophic Lake Aydat
(France). Annales des Sciences Naturelles Zoologie et Biologie Animale, 12, 99-105.

Janssen J. (1997) Comparison of response distance to prey via the lateral line in the ruffe and yellow perch. Journal of Fish Biology, 51, 921-930.

Kangur K., Kangur A. \& Kangur P. (1999) A comparative study on the feeding of eel, Anguilla anguilla (L.), bream, Abramis brama (L.) and ruffe, Gymnocephalus cernuus (L.) in Lake Vortsjarv, Estonia. Hydrobiologia, 408-409, 65-72.

Kolar C.S., Fullerton A.H., Martin K.M. \& Lamberti G.A. (2002) Interactions among zebra mussel shells, invertebrate prey, and Eurasian ruffe or yellow perch. Journal of Great Lakes Research, 28, 664-673.

Maitland P.S. \& East K. (1989) An increase in the number of ruffe, Gymnocephalus cernua (L.), in a Scottish loch from 1982-1987. Aquaculture and Fisheries Management, 20, 227-228.

Ogle D.H., Selgeby J.H., Newman R.M. \& Henry M.G. (1995) Diet and feeding periodicity of ruffe in the St Louis River Estuary, Lake Superior. Transactions of the American Fisheries Society, 124, 356-369.

Persson L. (1979) The effects of temperature and different food organisms on the rate of gastric evacuation in perch (Perca fluviatilis). Freshwater Biology, 9, 99-104.

Persson L. (1986) Effects of reduced interspecific competition on resource utilization in perch (Perca fluviatilis). Ecology, 67, 355-364.

Pratt D.M., Blust W.H. \& Selgeby J.H. (1992) Ruffe, Gymnocephalus cernuus: Newly introduced in North America. Canadian Journal of Fisheries and Aquatic Sciences, 49, 1616-1618.

Roesch R. \& Schmid W. (1996) Ruffe (Gymnocephalus cernuus L.), newly introduced into Lake Constance: preliminary data on population biology and possible effects on whitefish (Coregonus lavaretus L.). Annales Zoologici Fennici, 33, 467-471.

Savino J.F. \& Kolar C.S. (1996) Competition between nonindigenous ruffe and native yellow perch in laboratory studies. Transactions of the American Fisheries Society, 125, 562-571.

Thorpe J.E. (1977) Morphology, physiology, behavior, and ecology of Perca fluviatilis L. and P. flavescens Mitchill. Journal of the Fisheries Research Board of Canada, 34, 1504-1514.

Wetzel R.G. (2001) Limnology. Lake and River Ecosystems, 3rd edn. Academic Press, London.

(Manuscript accepted 1 November 2005) 